Jurnal SEMAR Vol. 9 No. 1 , hal. $19-26$

ISSN: 2302-3937 | Copyright (C LPPM Universitas Sebelas Maret Homepage: https://jurnal.uns.ac.id/jurnal-semar

\title{
OPTIMALISASI POTENSI PARIWISATA DAN LINGKUNGAN MELALUI PROGRAM PENDIDIKAN, KESEHATAN, DAN PEMBERDAYAAN
}

\author{
Okid Parama Astirin ${ }^{1,2^{*}}$ | Setya Nugraha Rahning Utomowati $^{2,3}$ \\ ${ }^{1}$ Program Studi Biologi, FMIPA \\ ${ }^{2}$ Pusat Penelitian Lingkungan Hidup, Lembaga Penelitian dan Pengabdian Masyarakat \\ ${ }^{3}$ Program Studi Geografi, FKIP \\ Universitas Sebelas Maret, Surakarta
}

\begin{abstract}
Buku Limau village is located at Belitung Timur district. This village is one out of 18 remoted villages which located in one region of Bangka Belitung Province. Buku Limau village is also one out of three villages which are populated by the people. One of the greatest potential of this village is tourism, which have a very lovey beaches all along the coast line. However, it seems that they do not have an adequate number of human resources. The purpose of this students community service programme is to increase the awereness of Buku Limau people in several important aspects, namely: education, tourism, well-being based on local wisdom. In order to increase those several aspects, the students will held several comunnity job, namely: first aid training, training and education for tourism human resources. These several community service will helped the people of Buku Limau to increase their wealth and boost the tourism programme.
\end{abstract}

Kata Kunci: Desa Buku Limau, Kecamatan Manggar, Kabupaten Belitung Timur, Wisata alam

\section{Pendahuluan}

Kabupaten Belitung Timur terletak di Provinsi Bangka Belitung. Kabupaten ini terdiri atas 7 kecamatan dan 39 desa. Jumlah penduduknya pada tahun 2017 mencapai 119.807 jiwa dengan luas wilayah $2.506,91 \mathrm{~km}^{2}$ dan sebaran penduduk $48 \mathrm{jiwa} / \mathrm{km}^{2}$. Kecamatan yang ada di Kabupaten Belitung Timur salah satunya ialah Kecamatan Manggar (Belitung Timur dalam Angka, 2014). Jumlah penduduk di pulau ini sebanyak 1.014 jiwa yang terdiri dari 515 jiwa laki-laki dan 499 jiwa perempuan dengan jumlah KK sebanyak 297 KK. Mayoritas mata pencaharian penduduk adalah nelayan dengan jumlah 95\% dan 5\% sisanya sebagai pegawai honorer/PNS (Nugroho et el., 2019). Kecamatan lainnya ialah Damar, Gantung, Kelapa Kampit, Simpang Pesak, dan Simpang Renggiang. Kabupaten Belitung Timur pada bagian utara berbatasan dengan Laut Natuna. Bagian Timur berbatasan dengan Selat Karimata. Bagian Selatan berbatasan dengan Laut Jawa. Bagian Barat berbatasan dengan Sijuk, Badau, dan Membalong. Kondisi ini menyebabkan daerah Kabupaten Belitung Timur sebagian besar adalah daerah pesisir karena dekat dengan laut. Kondisi demikian juga menjadi faktor penyebab berbedanya pola hidup dan aktivitas kehidupan masyarakat di Kecamatan Manggar, khususnya Desa Buku Limau dengan masyarakat di dataran rendah yang lain.

Buku Limau adalah sebuah desa yang berada di Kecamatan Manggar, Kabupaten Belitung Timur, Kepulauan Bangka Belitung. Buku Limau juga menjadi suatu desa kepulauan yang terdiri atas 18 pulau kecil yang relatif saling berjauhan. Pulau Buku Limau atau Desa Buku Limau adalah salah satu pulau dari 3 pulau yang berpenghuni dari total pulau yang ada (Wahyu et al., 2014). Pusat pemerintahan Desa Buku Limau berada di pulau dengan luas 50 Ha yang memerlukan jarak tempuh sejauh $12 \mathrm{~km}$ dari Kecamatan Manggar dengan waktu tempuh sekitar 40 menit (menggunakan transportasi air) (Nugroho et al., 2019).

\footnotetext{
*Penulis Korespondensi. Email: okid_parama@uns.ac.id
} 
Jurnal SEMAR Vol. 9 No. 1 , hal. $19-26$

Desa Buku Limau memiliki potensi wisata yang cukup tinggi. Hal ini karena desa berada di kepulauan yang memiliki garis pantai pasir putih dengan kawasan hutan mangrove sehingga memiliki keindahan alam yang menarik terutama panorama pantai. Banyak turis datang untuk berlayar ke Pulau Buku Limau, dengan jenis wisata memancing, berenang, snorkeling, berjemur, dll. Pasir putih dan air laut yang tenang merupakan ciri utama Pulau Buku Limau. Sepanjang pantai banyak jenis kayu mangrove seperti Vatica, Dipterocarpus, dll. Orang sering menggunakannya untuk membuat kapal. Berbagai jenis terumbu karang juga merupakan bagian utama pulau ini. Tumbuhnya mangrove memberi manfaat alami serta mampu melindungi dari erosi pantai. Mangrove dan terumbu karang berfungsi sebagai habitat dan tempat berpijah bagi banyak ikan. Ikan yang indah tinggal di sana. Beberapa ikannya diantaranya adalah Siganidae, Pteridae, Labradae, dan masih banyak lagi. Kebanyakan adalah ikan karang. Para nelayan lokal tidak tertarik untuk menangkap ikan-ikan ini. Itu berarti jumlah mereka tetap melimpah. Semua daya tarik itu membuat pulau ini sempurna bagi wisatawan. Dibalik kekayaan alam tersebut Desa Buku Limau tidak memiliki potensi sumber daya manusia yang unggul. Tingkat pendidikan yang rendah, kesehatan dan fasilitas kesehatan tidak lengkap. Oleh karena itu sangat diperlukan pemberdayaan masyarakat yang dilakukan oleh Perguruan Tinggi. Menurut Nugroho et al. (2019), Pulau Buku Limau hanya tersedia sarana pendidikan jenjang PAUD dan SD saja. Tidak adanya SMP, SMA dan jenjang pendidikan lebih tinggi setelah sekolah dasar membuat siswa SD di Pulau Buku Limau banyak yang tidak memiliki minat untuk melanjutkan ke jenjang berikutnya.

Kegiatan pengabdian masyarakat yang dilaksanakan dalam bentuk KKN tematik kemitraan UNS memiliki peran sebagai perantara dunia Perguruan Tinggi terhadap banyaknya permasalahan yang sering ditemukan dalam kelompok masyarakat yang akan mengembangkan daerahnya. Kelompok masyarakat ini sendiri terbagi dalam berbagai komunitas yang dapat dilihat sesuai dengan kebutuhan dan permasalahan, seperti masyarakat awam (dengan tingkat pendidikan kurang) akan sulit mengembangkan daerahnya meskipun memiliki potensi alam yang sangat baik. Dengan berbagai latar belakang tersebut, tim KKN-UNS lokasi Buku Limau menetapkan prioritas program dalam mengupayakan pengembangan potensi yang terdapat di kawasan tersebut. Dengan adanya pola ekowisata berbasis masyarakat bukan berarti masyarakat akan menjalankan usaha ekowisata sendiri, namun akan dilakukan pendampingan untuk pengembangan sistem dan optimalisasi potensi kekayaan sumber daya alam yang ada yaitu potensi perikanan, kehati terumbu karang maupun ekowisata mangrove (Wahyu et al., 2014). Tataran implementasi ekowisata perlu dipandang sebagai bagian dari perencanaan pembangunan terpadu yang dilakukan di suatu daerah baik yang dilakukan oleh masyarakat maupun pemangku kebijakan (stakeholder). Pecinta snorkling sudah disediakan fasilitas oleh pemerintah daerah setempat melalui Dinas Kebudayaan dan Pariwisata,yakni dengan membangun dive centre atau pusat selam di kawasan Pulau Buku Limau. Disbudpar Belitung Timur juga menyediakan 7 (tujuh) unit glass bottom boat atau kapal kaca (Anonim 2020).

Menurut Ferdinan et al (2015), diharapkan masyarakat di sekitar objek wisata alam dapat memperoleh keuntungan karena adanya lapangan pekerjaan yang akan meningkatkan pendapatan dan kesejahteraan masyarakat. Untuk itu, pelibatan para pihak terkait mulai dari level komunitas, masyarakat, pemerintah, dunia usaha dan organisasi non pemerintah diharapkan membangun suatu jaringan dan menjalankan suatu kemitraan yang baik sesuai peran dan keahlian masing-masing. Potensi wisata desa Buku Limau belum banyak tergarap dan belum banyak pula di ekspose secara apik di media online, sehingga informasi keindahan alam yang dimiliki belum sepenuhnya dapat diketahui oleh wisatawan atau orang luar daerah. Dalam pendekatan ekowisata, pusat informasi menjadi hal yang penting dan dapat juga dijadikan pusat kegiatan dengan tujuan meningkatkan nilai dari pengalaman seorang turis yang bisa memperoleh informasi yang lengkap tentang lokasi atau kawasan dari segi budaya, sejarah, alam, dan menyaksikan acara seni, kerajinan dan produk budaya lainnya.

\section{Metode Pelaksanaan}

Mahasiswa Pelaksana KKN sampai di Kecamatan Manggar, Belitung Timur pada tanggal 15 Januari 2020 bersama DPL untuk menyerahkan mahasiswa kepada Camat Manggar. Mahasiswa tiba di Desa Pulau Buku Limau pada tanggal 16 Januari 2020 disambut dengan Tarian Padupa yang merupakan 
Jurnal SEMAR Vol. 9 No. 1 , hal. $19-26$

tarian jamuan dari Suku Bugis untuk tamu yang hadir di Pulau tersebut. Pada hari itu pula, Camat Manggar melakukan penyerahan mahasiswa KKN UNS Periode Januari - Februari 2020 kepada Kepala Desa Buku Limau yang disaksikan oleh masyarakat setempat di Gedung Serba Guna Buku Limau. Tim Divisi Pemberdayaan Masyarakat dan Infrastruktur melakukan survey kepada masyarakat dan diskusi tertutup dengan perangkat desa sejak tanggal 20 Januari - 3 Februari 2020. Hasil diskusi tertutup kemudian disampaikan kepada Ketua RT dan/atau yang mewakili serta masyarakat pada umumnya di tanggal 4 Februari 2020 di Gedung Serba Guna Buku Limau yang disebut dengan Sosialisasi Desa Wisata. Output Sosialisasi Desa Wisata adalah rekomendasi rumah warga yang layak dijadikan homestay, rekomendasi nama warga yang siap menyediakan kuliner untuk optimalisasi kuliner lokal, rekomendasi optimalisasi Kelompok Sadar Wisata.

Program kerja KKN-thematik kemitraan dalam rangka untuk mencapai tujuan utama KKN yaitu Sosialisasi Desa Wisata, beserta persiapan yang dibutuhkan. Oleh karena itu dalam rangka pendukung tujuan tersebut, maka kegiatan dibagi menjadi 4 topik besar di mana di dalamnya terdapat beberapa sub-bagian atau sub-topik lagi, yang secara rinci sebagai berikut :

1. Bidang Pendidikan

a. Program Kelas Bahasa

b. Program Pendidikan Karakter

c. Program Kelas Baca

d. Program Pelatihan Kesenian

2. Bidang Kesehatan

a. Program Cek SaSet (Sabtu Sehat)

b. Program Parenting

c. Program Sosialisasi PHBS

d. Program Olahraga Rutin

3. Bidang Pemberdayaan Masyarakat

a. Program Pengolahan Air Laut

b. Program Buku Limau Recycle Centre

c. Program Tata Verti (Tanam Tingkat Verticulture)

d. Program Manajemen Pemasaran UMKM Lokal

e. Program Perencanaan dan penyusuna Peraturan Desa (Perdes)

f. Program dan Souvenir

4. Bidang Infrastruktur

a. Program Sosialisasi Bangun Rumah Ideal

b. Program Sosialisasi dan Workshop Eco-Brick

c. Program Landmark Desa

d. Program Sign System dan Mapping Desa

e. Program Festival Desa

Program kerja KKN ini didukung oleh 19 orang mahasiswa yang tinggal dilokasi selama 42 hari.

\section{Hasil dan Pembahasan}

Kegiatan KKN yang telah terlaksana berdasarkan permasalahan yang teridentifikasi dapat diselesaikan secara umum adalah meningkatkan dan menggiatkan wisata alam berdasarkan potensi yang terdapat di desa Buku Limau, Kecamatan Manggar, Belitung Timur. Dengan adanya potensi yang dapat dikembangkan dan semangat masyarakat setempat dan termasuk pemuka masyarakat, maka kegiatan dapat dikelompokkan menjadi 4 sub bidang. Keempat sub bidang tersebut adalah bidang yang mendukung perkembangan ekonomi dan pengembangan desa wisata yang dapat dilakukan masyarakat setempat. 
Jurnal SEMAR Vol. 9 No. 1 , hal. $19-26$

ISSN: 2302-3937 | Copyright (C LPPM Universitas Sebelas Maret Homepage: https://jurnal.uns.ac.id/jurnal-semar

Program kerja dikelompokkan menjadi 4 bidang. Secara rinci hasil yang diperoleh dapat dijelaskan.

\section{Pendidikan}

Sub program Kelas Bahasa: Kelas bahasa di latar belakangi oleh keadaan masyarakat Desa Buku Limau yang masih sangat minim menggunakan bahkan mengerti bahasa Indonesia, bahasa yang dipergunakan adalah bahawa melayu. Pelaksanaannya dengan mengajarkan penggunaan bahasa Indonesia yang baik dan benar khususnya kepada anak-anak SD 29 Manggar, baik saat di dalam maupun di luar kelas. Kegiatan ini telah berhasil dengan bertambahnya pemahaman masyarakat Desa Buku Limau khususnya anak-anak tentang penggunaan dan pentingnya bahasa Indonesia sebagai bahasa nasional dan bahasa pemersatu.
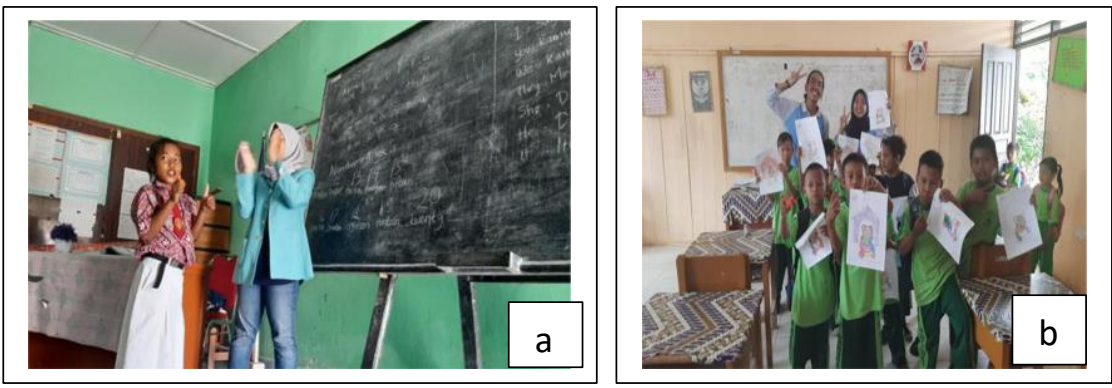

Gambar 1. Program kelas bahasa (a) siswa diberi pelajaran bahasa Inggris (b) kelas mewarna

Sub Program Pendidikan Karakter: Program ini dilakukan dengan mengutamakan dongeng yang bertujuan cerita yang dibawakan memiliki pesan baik yang ingin disampaikan atau biasa disebut moral value. Menanamkan nilai-nilai kebaikan untuk membentuk karakter anak-anak khususnya anak sekolah dasar di Pulau Buku Limau. Materi cita-citaku di SDN 29 Manggar, Siswa mewarnai kertas profesi berupa dokter, polisi, dan guru dan mewarnainya serta ditempel di mading sekolah. Materi sopan santun di SDN 29 Manggar. Karakter siswa yang sebelumnya sulit diatur menjadi mudah diatur.

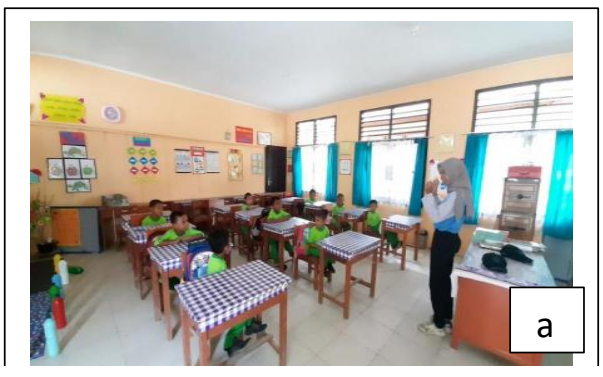

Gambar 2. Pendidikan karakter dan pengenalan potensi diri . (a) pemberian pelajaran secara umum (b) Keterampilan siswa dalam seni melipat dalam rangka untuk membentuk karakter anak

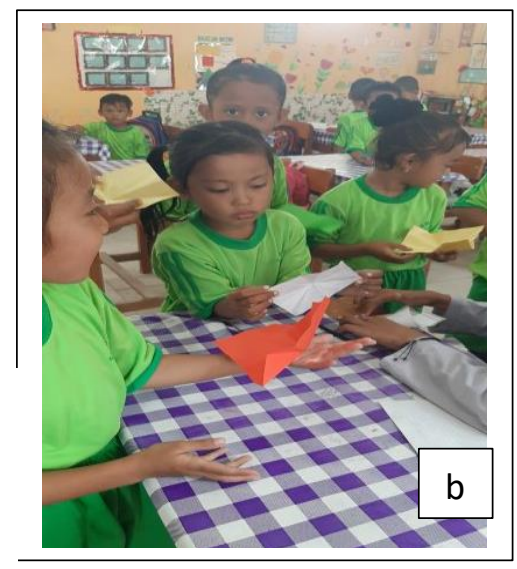

Sub Program Kelas Baca: Program pembangunan Kelas Baca ini dilatarbelakangi oleh kurangnya fasilitas literasi di Pulau Buku Limau. Kelas Baca ini diharapkan dapat memfasilitasi kegiatan literasi di Pulau Buku Limau untuk semua kalangan. Program ini nantinya akan dilanjutkan dan dikembangkan oleh pihak desa sebagai awal dibangunnya perpustakaan desa. Meningkatnya minat baca atau literasi masyarakat Pulau Buku Limau khususnya anak-anak agar dapat meningkatkan pengetahuan, kesadaran, kemauan masyarakat untuk belajar dan mencari ilmu sebanyak-banyaknya lewat buku. Materi pengenalan huruf kapital, huruf konsonan, dan tanda baca di SDN 29 Manggar. 

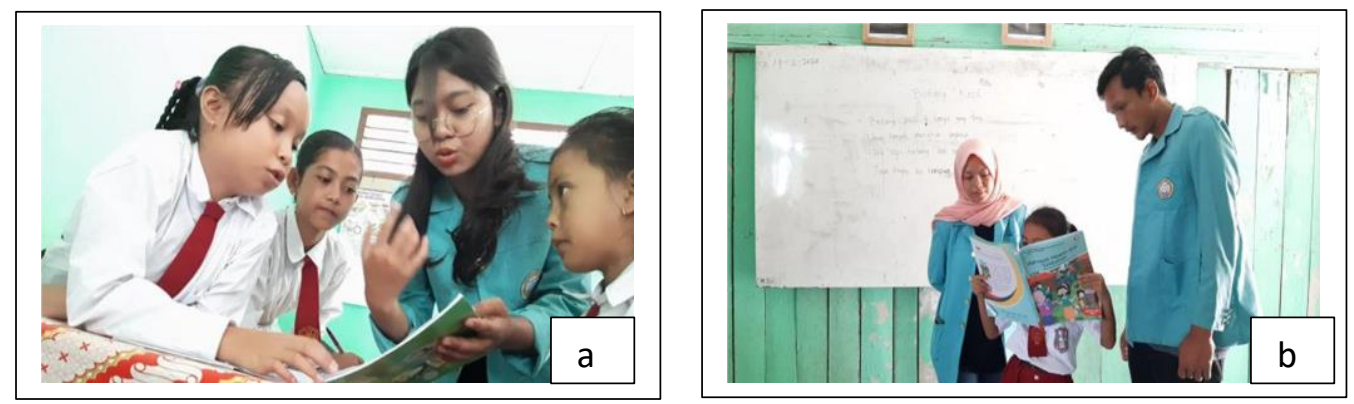

Gambar 3. Kelas Baca Tulis (a) Siswa Kelas 5 diajarkan memahami bacaan dengan baik dan benar (b) Siswa diajarkan membaca dan tampil di depan kelas

Sub Program Pelatihan Kesenian: Program kerja kesenian ini mempunyai tugas pokok membantu Kepala Desa dalam melaksanakan tugas di bidang pengembangan dan pelestarian seni budaya di Desa Buku Limau, menyelenggarakan sosialisasi, pembinaan dalam meningkatkan apresiasi seni budaya, menyelenggarakan koordinasi kegiatan apresiasi seni tradisional dan modern, menyelenggarakan peningkatan lembaga budaya dan kemitraan dengan berbagai pihak terkait, lembaga adat dan masyarakat. Masyarakat khususnya anak-anak mengetahui dan mempraktekkan bagaimana mengembangkan kesenian di Desa Buku Limau.

\section{Bidang Kesehatan}

Sub Program Cek SaSet (Sabtu Sehat) dan pola hidup bersih: Cek kesehatan merupakan kegiatan yang bertujuan untuk mengecek kesehatan pada masyarakat di Desa Buku Limau. Program Cek Kesehatan seharusnya dilakukan secara rutin oleh setiap manusia terkhusus manusia yang sudah memasuki umur 30 tahun. Cek Kesehatan mencakup pemeriksaan untuk layanan pencegahan klinis serta pengantisipasian kepada seseorang yang tidak memiliki tanda ataupun gejala sakit, hal ini adalah proses dari pemeriksaan kesehatan secara rutin. Keberhasilan program ini adalah mengadakan fasilitas pemeriksaan kesehatan yang dapat dimanfaatkan masyarakat Desa Buku Limau. Rt 07 dan Rt.08 di Rumah Bapak Abu. Kesehatan masyarakat terkontrol dan masyarakat paham penanganan dari penyakit asam urat dan hipertensi.

Sub Program Parenting: Program kerja ini berbentuk sosialisasi di mana masyarakat dapat belajar melalui interaksi dengan orang lain tentang cara berpikir, merasakan, dan bertindak yang bertujuan menghasilkan partisipasi sosial yang efektif. Program kerja ini berbentuk sosialisasi di mana masyarakat dapat belajar melalui interaksi dengan orang lain tentang cara berpikir, merasakan, dan bertindak yang bertujuan menghasilkan partisipasi sosial yang efektif.

Sub Program Sosialisasi PHBS: Program kerja ini berbentuk sosialisasi dan bertujuan adanya kesadaran pada diri individu di dalam keluarga maupun di masyarakat, yang menjadikan seseorang atau keluarga dapat menolong diri sendiri di bidang kesehatan dan berperan aktif dalam kegiatan-kegiatan kesehatan di lingkungannya. Menghasilkan pemahaman tentang pentingnya menjaga kesehatan diri, lingkungan dan senantiasa menghindarkan diri dari penyakit. Penyampaian materi 8 poin PHBS di sekolah, dilanjutkan dengan prakter mencuci tangan menggunakan lagu "7 langkah mencuci tangan" di SDN 29 Manggar.
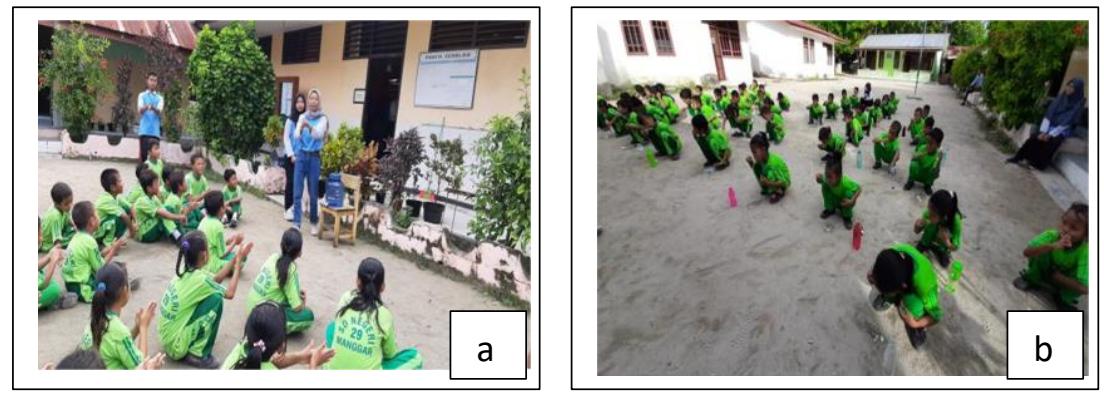

Gambar 4. Pola hidup bersih (a) Praktik cuci tangan yang baik dan benar (b) Praktik sikat gigi yang baik dan benar selepas olahraga rutin 
Jurnal SEMAR Vol. 9 No. 1 , hal. $19-26$

Sub Program Olahraga Rutin: Program kerja ini bertujuan agar masyarakat memiliki tubuh yang sehat di mana teknisnya diadakan olahraga secara teratur selama 30 menit yang terdiri dari jenis olahraga seperti bola voli, sepak bola, senam pagi, dan lari pagi. Menghasilkan kesadaran terhadap pentingnya berolahraga.

\section{Program Pemberdayaan Masyarakat}

Sub Program Pengolahan Air Laut: Program kerja ini berbentuk sosialisasi pengenalan mesin filtrasi air laut seperti bagaimana prinsip kerjanya, komponennya, cara memperbaikinya dan fungsi perkomponennya seperti apa dan workshop pembuatan alat. Masyarakat Desa Buku Limau dapat memperbaiki mesin pengolah air dan mngolah air laut menjadi air tawar secara mandiri.

Sub Program Buku Limau Recycle Centre: Recycle Centre adalah tempat pengolahan sampah yang telah terpilah menurut jenis sampah. Selain bisa sebagai sarana untuk melakukan gerakan penghijauan, pengelolaan sampah juga bisa menjadi sarana pendidikan gemar menabung untuk masyarakat dan anakanak. Metode Bank Sampah juga berfungsi untuk memberdayakan masyarakat agar peduli terhadap kebersihan. Terciptanya kesadaran akan lingkungan yang bersih.

Sub Program Tata Verti (Tanam Tingkat Verticulture): Program kerja ini berbentuk sosialisasi dan pelatihan yang didasarkan Desa Buku Limau merupakan desa yang relatif sempit karena berada di suatu pulau kecil sehingga kondisi ini memaksa masyarakat Desa Buku Limau untuk mengurungkan keinginannya untuk bercocok tanam. Keberhasilan dari pelaksanaan program ini adalah Masyarakat dapat memanfaatkan lahan di desa buku limau secara optimal yang diharapkan mampu memenuhi kebutuhan pangan.

Sub Program Manajemen Pemasaran UMKM Lokal: Program kerja ini berbentuk sosialisasi atas dasar Desa Buku Limau mempunyai potensi pada pengembangan olahan laut, tetapi masih membutuhkan beberapa pengembangan terutama pada sektor penjualan dan distribusinya. Nilai positif yang diperoleh masyarakat adalah Peningkatan produksi dan pasar penjualan produk khas Desa Buku Limau.

Sub Program Perencanaan dan penyusuna Peraturan Desa (Perdes): Dasar dari hadirnya perencanaan dan penyusunan peraturan desa ini bermula dari permintaan Camat Manggar terhadap tim survei tim KKN Buku Limau 2020. Terbentuknya Peraturan desa yang dapat membuat pola hidup maupun pola bermasyarakat di desa Buku Limau dapat menjadi lebih baik tanpa meng ubah kultur masyarakat di wilayah tersebut.

Sub Program Bumdes dan Souvenir: Dasarnya pendirian BUMDES dilakukan untuk meningkatkan kesejahteran masyarakat desa dengan melalui pengelolaan potensi desa sesuai dengan kebutuhan masyarakat, meningkatkan penghasilan, tetapi juga menyumbang penyerapan tenaga kerja. Banyak orang di desa yang akhirnya bisa mendapatkan perkerjaan dengan adanya BUMDES. Adanya peluang usaha yang akan meningkatkan perekonomian, pendapatan dan meng optimalkan potensi sumber daya alam untuk kebutuhan masyarakat, menjadi alat pemerataan dan pertumbuhan ekono mian desa.

Sub Program Sosialisasi dan Workshop Eco-Brick: Program kerja dilaksanakan dalam bentuk sosialisasi atas dasar kesadaran terhadap lingkungan sangat rendah, masyarakat cenderung tak acuh terhadap limbah plastik yang ada di sekitarnya serta atas dasar acuan pada RPJMD Kabupaten Belitung Timur tahun 2016-2021. Upaya pengurangan tumpukan sampah yang dominan berupa limbah plastik dan juga sebagai salah satu upaya menyelamatkan lingkungan di Desa Buku Limau. 
Jurnal SEMAR Vol. 9 No. 1 , hal. $19-26$

ISSN: 2302-3937 | Copyright (C LPPM Universitas Sebelas Maret

Homepage: https://jurnal.uns.ac.id/jurnal-semar

\section{Program Infrastruktur}

Sub Program Sosialisasi Bangun Rumah Ideal: Program kerja dilaksanakan dengan sosialiasi mengenai pentingnya konstruksi rumah yang tahap bencana dan tentang pentingnya layout atau penataan ruangan di rumah panggung guna keamanan dan kenyamanan pengguna. Menghasilkan sebuah pemahaman terhadap sebuah pengetahuan terhadap bangunan ideal yang tahan terhadap bencana.

Sub Program Landmark Desa: Landmark yang diadakan yaitu dalam bentuk revitalisasi dermaga dan juga pembuatan sculpture atau monumen yang terbuat dari hasil pengolahan kembali sampah yaitu ecobrick di mana program kerja dikolaborasikan bersama masyarakat dan mitra-mitra yang berpartisipasi. Keberhasilan program ini ditandai dengan pemahaman akan potensi wilayah dan semakin kuatnya karakter dari masyarakat Desa Buku Limau.

Sub Program Sign System dan Mapping Desa: Pembuatan sign system menggunakan bambu yang dipasang menggunakan semen dan membuat petunjuk arah menggunakan papan kayu yang bertuliskan penunjang sarana seperti tempat makan, toilet umum, restoran, dan lain-lain dengan tujuan menjadi salah satu penunjang sarana yang befungsi sebagai penanda maupun penunjuk jalan yang dapat memudahkan wisatawan lokal maupun mancanegara untuk mencari tempat yang akan mereka datangi. Terselesaikannya peta desa guna menjadi pelengkap aset desa yang kemudian diserahkan kepada kepala Desa dan disimpan di kantor desa Buku Limau.

Festival Desa Acara puncak dari suatu rangkaian acara selama beberapa hari pada minggu terakhir pelaksanaan KKN di mana akan diadakan launching produk khas dari Desa Buku Limau, persembahan kesenian, awarding kompetisi olahraga, dan penyerah terimaan hasil rancangan dari proker kemitraan tim KKN dengan Pemerintah Desa Buku Limau. Acara puncak dari suatu rangkaian acara selama beberapa hari pada minggu terakhir pelaksanaan KKN di mana diadakan launching produk khas dari Desa Buku Limau, persembahan kesenian, awarding kompetisi olahraga, dan penyerah terimaan hasil rancangan dari proker kemitraan tim KKN dengan pemerintah Desa Buku Limau.

\section{Keberlajutan Program Kerja}

Beberapa program kerja telah dirancang dan dilaksanakan berdasarkan identifikasi kondisi masyarakat di Desa Buku Limau. Dengan demikian, program kerja tersebut diharapkan dapat memberikan kontribusi yang berkelanjutan dalam pembangunan kemandirian masyarakat Desa Buku Limau. Adapun hasil yang diharapkan melalui program $\mathrm{KKN}$, antara lain:

1. Masyarakat di Kecamatan Manggar terutama di Desa Buku Limau, dapat mengembangkan pariwisata yang mereka miliki dan kemampuan dalam mengelola wisata mereka dengan baik.

2. Masyarakat di Desa Buku Limau dapat mengerti pentingnya kesehatan dan kebersihan lingkungan.

3. Meningkatkan pendidikan dasar tentang Bahasa inggris, ekonomi, dan lainnya. Program KKN-tematik kemitraan telah dilaksanakan selama 45 hari di Desa Buku Limau.

Setelah pelaksanaan semua program selesai masyarakat Desa Buku Limau mampu mengembangkan potensi pariwisata yang mereka miliki dan kemampuan dalam mengelola wisata mereka dengan baik serta menjaga lingkungan. Selain itu di Desa Buku Limau dapat dijadikan penghasilan dari wisatawan yang mengunjungi wisata Buku Limau dan terus mengembangkan usaha kecil menengah tersebut menjadi penghasilan dan menjadi daya tarik wisatawan dalam mengunjungi wisata Pulau Buku Limau. Ketika program tersebut selesai bukan berarti permasalahan yang ada dapat langsung terselesaikan, maka dari itu dibutuhkan rencana jangka panjang untuk benar-benar membawa desa ini kepada kondisi yang lebih baik. Kedepannya keterlibatan dan kerjasama antara warga serta pemerintah setempat sangat dibutuhkan, sehingga warga Pulau Buku Limau mampu untuk mengelola sektor pariwisata dan menjaga 
Jurnal SEMAR Vol. 9 No. 1 , hal. $19-26$

ISSN: 2302-3937 | Copyright (C LPPM Universitas Sebelas Maret Homepage: https://jurnal.uns.ac.id/jurnal-semar

lingkungan dengan baik.

\section{Referensi}

Anonim, 2019, Kabupaten Belitung Timur Dalam Angka 2019 ISSN: 2356-BPS Kabupaten Belitung Timur, CV.Winner

Anonim, 2020, Surga Bawah Laut Pulau Buku Limau Beltim, https://rri.co.id/rona/ budaya-dan-wisata/ 790900/surga-bawah-laut-pulau-buku-limau-beltim, 2020, Copyrights RRI.co.id.

Anonim, 2020, Direktori Pulau-Pulau Kecil Indonesia http://www.ppk-kp3k.kkp.go.id/direktoripulau/index.php /public_c/pulau_info/2257

Ferdinan Y, M Makmur dan H. Ribawanto, 2015, Pengembangan Wisata Alam Berbasis Ekowisata Dalam Perspektif Pelayanan Publik (Studi Pada Disparbud Kabupaten Nganjuk), Jurnal Administrasi Publik (JAP), Vol. 3, No. 12, Hal. 2123-2127

Nugroho F.O., D.S Sumitro, dan Barika, 2019, Perubahan Fasilitas Perpustakaan Terhadap Minat Baca Siswa Dipulau Buku Limau, Jurnal Abdimas Volume 5 Nomor 3, Maret 2019, hal 207-211

Visit Bangka Belitung http://www.visitbangkabelitung.com/content/pulau-buku-limau

Wahyu A, Reniati dan Sabri F., 2014, Model Pengembangan Ekonomi Daerah Pesisir Dan Pulau-Pulau Kecil Melalui Pendekatan Integrasi Marine-Tourism Industry Di Desa Baru Dan Buku Limau Kecamatan Manggar Kabupaten Belitung Timur, Vol 1, No 1 (2014), Jurnal Pengabdian Kepada Masyarakat Universitas Bangka Belitung 